\title{
Erratum 1: Centrally administered adrenomedullin 5 activates oxytocin-secreting neurons in the hypothalamus and elevates plasma oxytocin level in rats
}

\author{
H Otsubo, S Hyodo, H Hashimoto, M Kawasaki, H Suzuki, T Saito, T Ohbuchi, T Yokoyama, H Fujihara, \\ T Matsumoto, Y Takei and Y Ueta
}

The authors and the journal apologise for errors that have occurred in this paper published in 2009202 237-247.

The following sentence in the abstract should read as
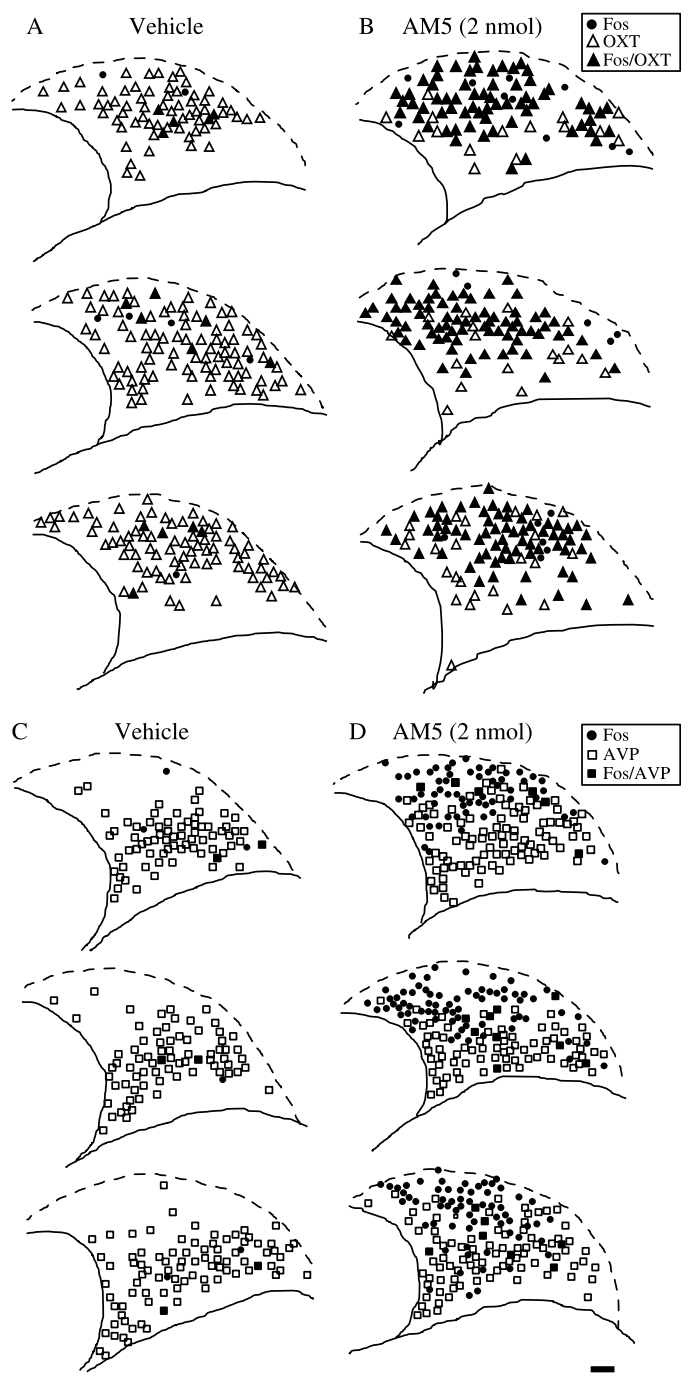

Figure 4 Topographical mapping of Fos-LI and OXT-LI or AVP-LI in the SON 90 min after i.c.v. administration of vehicle (A and C) or AM5 ( $2 \mathrm{nmol} / \mathrm{rat}$ : B and D). (A and B) Coexistence of Fos-LI and OXT-LI ( $\mathbf{\Delta})$. (C and D) Coexistence of Fos-LI and AVP-LI -, Fos-LI-positive cells; $\Delta$, OXT-LI-positive cells: $\square$, AVP-LI-positive cells. In each panel, two 30- $\mu$ m thick coronal sections from the SON were selected. Bar indicates $50 \mu \mathrm{m}$.
This induction was significantly but not completely reduced by pre-treatment with both the calcitonin gene-related peptide (CGRP) antagonist CGRP-(8-37) (3 nmol/rat) and the AM receptor antagonist AM-(22-52) $(27 \mathrm{nmol} / \mathrm{rat})$.

and not as published.

Further the keys to panel D of Figs 4 and 5 were also wrong. The correct figures are published in full below:
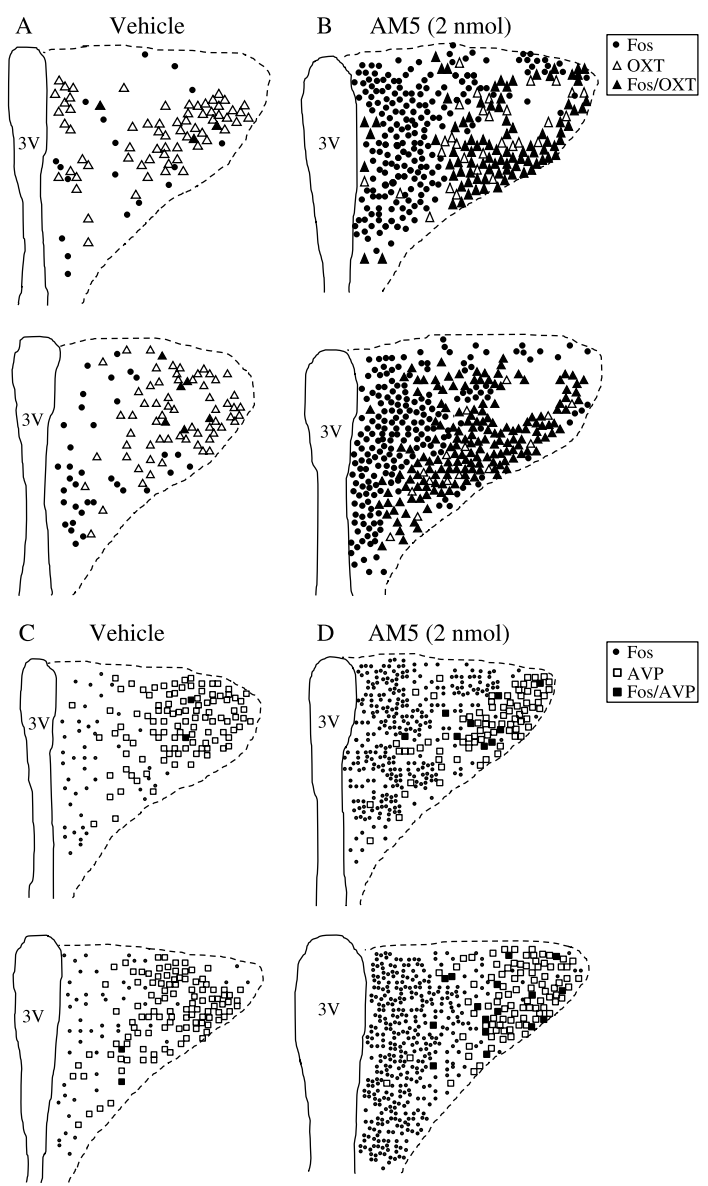

Figure 5 Topographical mapping of Fos-LI and OXT-LI or AVP-LI in the PVN $90 \mathrm{~min}$ after i.c.v. administration of vehicle (A and C) or AM5 (2 nmol/rat: B and D). (A and B) Coexistence of Fos-LI and OXT-LI ( $\mathbf{\Delta}$ ). (C and D) Coexistence of Fos-LI and AVP-LI ( $\square$ ). -, Fos-LI-positive cells; $\Delta$, OXT-LI-positive cells; $\square$, AVP-LI-positive cells. In each panel, two 30- $\mu$ m thick coronal sections from the PVN were selected. Bar indicates $50 \mu \mathrm{m}$. 